\title{
O uso medicinal de pedras bezoares na obra Paraguay Natural Ilustrado, de José Sánchez Labrador, S.J. (1771) ${ }^{1}$
}

\author{
The medicinal use of bezoar stones in the work Paraguay Natural \\ Ilustrado, by José Sánchez Labrador, S.J. (1771)
}

\author{
ELIANE CRISTINA DECKMANN FLECK \\ Universidade do Vale do Rio dos Sinos | UNISINOS
}

\begin{abstract}
RESUMO Este artigo apresenta análise do manuscrito Paraguay Natural Ilustrado, obra escrita pelo padre jesuíta José Sánchez Labrador, entre os anos de 1771 e 1776, na qual ele descreve a fauna e a flora das regiões da Província Jesuítica do Paraguai, bem como as práticas terapêuticas adotadas pelos grupos indígenas junto aos quais atuou como missionário. Dentre os saberes e as práticas curativas dos nativos americanos, Labrador destacou o uso medicinal das pedras bezoares, prática terapêutica sobre a qual nos debruçaremos mais detidamente, contemplando tanto as descrições que constam no sétimo Capítulo - De las Piedras Bezares - do primeiro Livro da Terceira Parte da obra, intitulado Animais quadrúpedes, quanto as referências que o jesuíta faz a elas no quinto Capítulo do Terceiro Livro da Segunda Parte do Paraguay Natural Ilustrado.
\end{abstract}

Palavras-chave Paraguay Natural Ilustrado - América Platina - pedras bezoares - virtudes medicinais.

\begin{abstract}
This article presents an analysis of the manuscript Paraguay Natural Ilustrado, work written by Jesuit priest José Sánchez Labrador, between the years 1771 and 1776, in which he describes the fauna and flora of the regions of the Jesuit Province of Paraguay, as well as the therapeutic practices adopted by the indigenous groups alongside which he acted as a missionary. Among the knowledge and the healing practices of the natives, Labrador highlighted the medicinal use of the bezoar stones, a practice on which we detain ourselves more closely, contemplating the descriptions that are part of the seventh Chapter - De las Piedras Bezares - of the first Book of the Third Part of the work, entitled Animais quadrúpedes, as well as the references the Jesuit makes to them in the Fifth Chapter of the Third Book of the Second Part of Paraguay Natural Ilustrado.
\end{abstract}

Keywords Paraguay Natural Ilustrado - Platin America - bezoar stones - medicinal virtues.

\section{Uma breve introdução: sobre José Sánchez Labrador e o Paraguay Natural Ilustrado}

Assim, como muitos outros padres e irmãos jesuítas que o precederam nas terras de missão na América, José Sánchez Labrador não dedicou-se, exclusivamente, à conversão dos indígenas, mas também ao estudo da fauna e da flora americana que observou nas diversas regiões da Província Jesuítica do Paraguai em que atuou como missionário. 0 autor de Paraguay Católico e de Paraguay Natural Ilustrado nasceu em La Guardia, cidade de La Mancha, no dia 19 
de setembro de 1714 ou de 1717. De acordo com o historiador argentino Aníbal Ruiz Moreno (1948), ${ }^{2}$ ingressou na Companhia de Jesus em 5 de outubro de 1731, e segundo o historiador espanhol Héctor Sainz Ollero (1989), ${ }^{3}$ isto se deu em 19 de setembro de 1732. Iniciou seus estudos de Filosofia no Colégio de Valladolid, interrompendo-os para viajar ao Rio da Prata em 1734, acompanhando o padre Antonio Machoni. ${ }^{4}$ De 1734 a 1739, estudou Filosofia e Teologia na Universidade de Córdoba, concluindo sua formação no verão de 1739. Entre os anos de 1741 e 1744, atuou como professor na mesma cidade, dedicando-se, concomitantemente, aos estudos de História Natural.

De acordo com seus biógrafos, entre 1747 e 1757, o padre jesuíta atuou junto às reduções de Yapeyu, Trinidad, Jesús, Loreto, San Ignacio Mini, San Ignacio Guazu, San Cosme y San Damián e San Lorenzo, convivendo, assim, com indígenas Guaranis, Zamucos, Chiquitos, Mbayás e Guaicurús. A partir de 1757, passou a atuar em Apóstoles (Santos Apóstolos ou Apóstolos São Pedro e São Pablo), tendo como companheiros os padres Lorenzo Ovando e Segismundo Asperger, este último, reconhecido por sua atuação como médico e boticário.

Em 14 de agosto de 1767, ao regressar de uma viagem à região de Chiquitos, foi informado do decreto da expulsão ${ }^{5}$ dos jesuítas do império colonial espanhol. ${ }^{6}$ Em $1768,{ }^{7}$ chegou à Itália, se estabelecendo em Ravena, onde foi Superior de uma das casas que a Companhia de Jesus possuía na cidade. Manteve-se neste desterro por 30 anos, período durante o qual se dedicou a escrever, sendo que entre suas principais obras está Paraguay Natural Ilustrado, manuscrito que permanece inédito. ${ }^{8}$ Sánchez Labrador morreu em Ravena, em 10 de outubro de 1798.

Escrita entre os anos de 1771 e 1776, esta obra conta com 100 ilustrações feitas pelo próprio autor e divide-se em quatro partes. A primeira possui 558 páginas e divide-se em três Livros: Diversidade de terras e corpos terrestres; Água e várias coisas a ela pertencentes; e Ar, ventos, estações do ano, clima destes países e enfermidades mais comuns. A segunda Parte conta com 500 páginas e trata, especificamente, da Botânica. A terceira se divide nos seguintes livros: Animais quadrúpedes (166 páginas); as Aves (127 páginas); e os Peixes (128 páginas). A quarta e última Parte da obra, que possui 373 páginas, conta com os livros: Os Animais anfíbios; os Animais répteis; e os Insetos.

0 primeiro Livro da Terceira Parte da obra, intitulado Animais quadrúpedes, ${ }^{9}$ conta com um capítulo, 0 sétimo, intitulado De las Piedras Bezares, que trata, especificamente, das origens dos bezoares, das falsificações, das espécies de bezoares, de suas virtudes e de outros tipos dessas pedras. Vale ressaltar que ao longo do quinto capítulo do terceiro Livro da Segunda Parte do Paraguay Natural Ilustrado, o jesuíta faz também referências às virtudes medicinais das pedras bezoares e a sua utilização tanto por europeus e orientais, quanto pelos indígenas da Província Jesuítica do Paraguai. É sobre as descrições das virtudes terapêuticas das pedras bezoares e sua indicação no tratamento de certas enfermidades que nos deteremos na continuidade.

\section{Sobre origens, falsificações e virtudes das pedras bezoares}

Desde a Antiguidade, as pedras bezoares - "concreções formadas por camadas de lâminas calcárias sobrepostas" -, especialmente as que se formavam nos estômagos de veados e cabras, foram empregadas no tratamento de uma série de enfermidades, ${ }^{10}$ creditando-se a elas "o poder de opor-se aos envenenamentos". ${ }^{11}$ A eficácia contra envenenamentos logo se espalhou pela Ásia e chegou à Europa, onde seu largo uso fez com que as mezinhas ${ }^{12}$ utilizadas contra venenos fossem chamadas de "bezedáricas" pelos boticários, médicos e naturalistas do século XVI.

As pedras bezoares eram definidas a partir de sua localização geográfica, sendo que as Ocidentais eram as formadas nos estômagos de animais americanos, mais comumente em cervos e cabras americanos, alpacas, Ihamas, vicunhas, guanacos e antas, enquanto que as Orientais eram aquelas encontradas nos estômagos das cabras da Ásia central e da Europa, consideradas secundárias. Segundo Sánchez Labrador, o Bezoar Oriental se formava no estômago de um animal - o Pasén ou Cabra das Índias, que habitava o Laar, Província da Pérsia -, que teria sido descrito pelo médico Jacobo Boncio, ${ }^{13}$ para quem esta cabra não diferia das da Europa, a não ser por seus chifres 
maiores e por ter o pelo manchado como o do tigre. Para o jesuíta, os bezoares orientais eram muito raros, até mesmo entre os persas, o que fazia com que nas boticas e oficinas europeias muito raramente se encontrasse uma pedra bezoar oriental genuína.

Já a Pedra Bezoar Ocidental ou a Americana se formariam no estômago de um animal chamado de Capricerva Ocidental ou Cervo Menor Americano Bezoárdico, Mazama, Cervo e Cabra do Brasil. Sánchez Labrador diz que autores como Guillermo Piso ${ }^{14}$ e Georg Marcgrav ${ }^{15}$ chamavam este animal de Cuquazuete e Cuguazuapara, sendo estas duas espécies de cervo. De acordo com Piso, os pelos destes animais eram lustrosos, curtos e de coloração parda e branca e que seus filhotes contavam com uma grande variedade de pintas que se mesclavam com o passar do tempo. 0 jesuíta critica as denominações errôneas - de Ysard Camoscio ou Cabra del Peru - dadas a estes animais que, na verdade, eram vicunhas:

Las vicuñas crían en sus estómagos Piedra Bezoar, y es la mas estimada. Formase por la calidad de los pastos, de que estos animales se alimentan. Se aumenta sobreponiéndose costras a costras. Por esto quanto mas vieja es la vicuña, tanto mayor es la Piedra Bezoar que se le encuentra. ${ }^{16}$

Tratando dos guanacos, em específico, ele comenta que podiam produzir pedras bezoares bastante grandes e que, no Peru, um índio teria mostrado as virtudes das pedras bezoares aos espanhóis e que, por isto, sua vida e a de seus companheiros foram poupadas. ${ }^{17}$ Em carta escrita a Sánchez Labrador, o padre José Cardiel ${ }^{18}$ informa que "En las tierras de los Patagones se crían guanacos de cuyas pieles hacen sus mantas. Con estas mantienen trato con las demás naciones. También venden las piedras bezares, que sacan de dichos animales, entre las cuales algunas son grandes y de muchas onza de pesos". ${ }^{19}$ Informações sobre a prática de extração destas pedras, que se formavam no estômago destes animais, e sua utilização terapêutica e posterior comercialização, podem ser também encontradas na obra Ensayo sobre la História Ntural del Gran Chaco, escrita pelo jesuíta José Solis, durante seu exílio em Faenza, na Itália. Nela, o missionário refere 0 uso de " animales em la cura de diversos trastorno desde las famosas piedras bezoares hasta los corazones y excrementos de aves". ${ }^{20}$

Também o padre Falkner ${ }^{21}$ refere a formação de pedras bezoares nos estômagos de antas e sua utilização pelos indígenas da Patagônia:

Hay tambien mucha caza menor, de que viven principalmiente los indios. Encuentrase igualmente gran cantidad de bezoar, no solo en los estômagos de los guanacos, vicuñas, sino tambien en los del anta, aunque el de este es mas ordinaria y comun. Cuando se administra en cantidad considerable, promueve muy bien un diaphoresis. Experimente que daba grande alivio en los dolores de estómago, desmayos. Su dosis consiste en una dracma, ó dus escrupulos, tomado en cualquiera cosa; bien que se podria administrar mayor cantidad con toda seguridad. En muchos casos vale mas que el polvo de oculi, cancron, ó polvos de testaceos, y otras sustancias minerales. He tenido algunas de estas piedras que pesaban 18 onzas. ${ }^{22}$

Para explicar a causa da incidência de bezoares em algumas regiões da América - em detrimento de outras -, Sánchez Labrador recorre ao relato do padre Alonso de Ovalle ${ }^{23}$, "que alega [...] que en tales sítios corriendo los Huanacos, heridos dela repetidas picaduras de las Bivoras, buscan al punto húerbas salutíferas". ${ }^{24}$ Também o padre Pedro Lozano, ${ }^{25}$ em sua obra Historia de la Conquista del Paraguay, Río de la Plata y Tucumán ${ }^{26}$ afirmaria que:

La materia de que forman dichas piedras son yerbas de gran virtud, que por instinto natural buscan (los animales) o para curarse, o para preservarse de sus ataques, o para impedir que llegue al corazón la ponzoña de víboras o arañas venenosas que pican, y es cosa experimentada que en los países donde abundan más los animales ponzoñosos, es también mayor la copia de piedras bezoares, como se ve en los guanacos en Chile, reyno muy limpio en sabandijas, se encuentran muy raras, pero en esta parte de la Cordillera, como es mucho mayor el número de vivientes nocivos, se hallan los bezares con mucha abundancia. ${ }^{27}$ 
Portanto, a presença de víboras na região que abrangia a então Província Jesuítica do Paraguai - o País de las Bivoras e de muitas outras espécies venenosas - favorecia a formação de bezoares nos estômagos de animais, inclusive, no Cuy, um mamífero roedor. ${ }^{28}$ Já as regiões da Província do $C h i l{ }^{29}$ e, especialmente, as terras próximas ao Estreito de Magalhães, que possuíam clima excessivamente frio e pouco propício às víboras, contariam com uma quase inexistente produção de pedras bezoares, que se formariam, preferencialmente, onde "abundan semejantes Reptiles nocivos" ${ }^{30}$

Sánchez Labrador, aliás, manifesta sua estranheza diante da constatação de que nenhum dos estudiosos por ele referidos fez referência aos bezoares dos guanacos, das antas ou das gran bestias, aventando a possibilidade de que estes autores tenham achado suficiente citar apenas os cervos como representantes de todos estes. 0 jesuíta chega a comparar estes estudiosos com os antigos gregos e latinos, que também não referiram as pedras bezoares orientais e nem os animais que as produziam, não descuidando de observar que a ausência de informações sobre elas não indicava que não existissem nesse período.

As pedras encontradas no Peru ${ }^{31}$ e no Paraguai possuíam em seu interior, segundo Labrador, um corazon de toda la massa ou ponto de apoio para a formação das capas do bezoar. Segundo alguns estudiosos, os bezoares com virtudes mais eficazes eram os que possuíam uma coloração esverdeada e formato redondo, enquanto que os que apresentavam formato oval ou cilíndrico eram considerados inferiores. Porém, Sánchez Labrador argumenta que o formato do bezoar pouco ou nada influenciaria, pois suas virtudes provinham, exclusivamente, das ervas que o compunham e que as capas que formavam o bezoar não possuíam a mesma coloração, apresentando também tamanhos e formas diferentes. 0 jesuíta contesta a opinião do droguista francês Pierre Pomet, ${ }^{32}$ que defendia que cada animal bezoárdico produzia apenas uma pedra bezoar, envolvida por uma túnica ou membrana, afirmando que suas observações teriam comprovado o contrário.

De acordo com Labrador, coube aos árabes e aos modernos a identificação das virtudes medicinais do bezoar oriental e do bezoar ocidental, o que explicaria o grande número de palavras árabes a elas referidas, como Hager Alzbesahar, Piedra Alexipharmaca, Balzaha e bedezahar, que podiam ser encontradas no Tratado de Gaspar Bauhín. ${ }^{33}$ Tidos como mercadoria rara e muito preciosa tanto no mercado europeu, quanto no asiático, os bezoares foram colocados em uma categoria de "produtos suntuários e mágicos", dentre os quais se encontravam as "pedras preciosas e pérolas" e os "chifres de unicórnio". ${ }^{34}$ Labrador irá criticar esta percepção difundida por alguns autores da Antiguidade, para quem a pedra bezoar "se guindara à categoria de substância mitológica, através dos espíritos e animais que o produziam, ganhando, por isso, poderes mágicos", ${ }^{35}$ vinculando sua utilização à "credulidad, superticion, y impostura humana". ${ }^{36}$

No Paraguay Natural, ele ressalta que as pedras bezoares, encontradas em cabras ou cervos e, também, nos estômagos de bois, águias, caranguejos, cuis e porcos-espinho, ${ }^{37}$ eram medicinais, porque "formadas de algunos jugos de las hierbas saludables, que estos animales pacen, y ruminan". ${ }^{38}$ Ao longo do Terceiro Tomo de sua obra, Labrador traz informações sobre a formação da pedra bezoar, ressaltando que, quase sempre, em seu centro havia algum corpo estranho - corpo heterogêneo - que era formado por uma substância muito diferente da que compunha a pedra. Esse corpo heterogêneo poderia ser, por exemplo, uma semente de fruto, ao redor do qual se formaram as capas ou folhas bezoárdicas, que se constituiriam da seguinte maneira: o fruto ou planta, ingerido pelo animal, causaria a condensação dos licores que se encontravam no estômago, os quais, por sua natureza adstringente, favoreceriam a formação de uma matéria pegajosa e nitrosa, que se encaminharia para o piloro, ${ }^{39}$ onde se prenderia ao fruto ou à pedra que ali se encontrava, formando, assim, a primeira capa do bezoar, que daria origem ao restante da pedra.

No capítulo V, do Livro Três da Segunda Parte, intitulado Los Arboles en Particular, Sánchez Labrador também refere as pedras bezoares. Segundo o jesuíta, Esteban Geoffroy ${ }^{40}$ atribuía a origem das pedras bezoares às sementes das plantas Acácias ou Yobopeys, as quais, após serem ingeridas por certos animais, estariam sujeitas à ação dos ácidos existentes em seus estômagos, propiciando a formação das pedras bezoares. Para o jesuíta esta opinião não deveria ser completamente desconsiderada, contudo, suas observações haviam demonstrado que nem todas as regiões possuíam animais bezoárdicos e nem sempre eles eram encontrados onde existiam Acácias ou Ybopeys. ${ }^{41}$ 
Foi, justamente, por sua raridade e alto valor que as pedras bezoares passaram a ser alvo de frequentes falsificações. Este processo teria se iniciado entre os comerciantes persas, se aperfeiçoado entre os chineses e os malaios e se implantado no mercado europeu, onde já era muito difícil encontrar uma pedra bezoar verdadeira. Sánchez Labrador destaca que, na Europa, se adulteravam as pedras utilizando certos pós de Tea ${ }^{42}$ ou resina de Pino e de uma matéria viscosa. Entre os bezoares falsos citados pelo jesuíta estão as Pedras de Goa, ou de Malaca, as quais eram obtidas das pernas de caranguejos marinhos e de conchas, que eram reduzidas a um pó fino, ao qual era adicionado almíscar ${ }^{43} \mathrm{e}$ âmbar amarela, formando uma massa em que eram visíveis pelotas semelhantes a bezoares, as quais eram envolvidas em folhas de ouro. De acordo com Alves, os chineses "substituíam a genuína pedra bezoar por uma mistura de barro, cal e sangue seco de animais, com um pouco de pó da verdadeira pedra, como se fazia muitas vezes em Banten, porto javanês". ${ }^{4}$ De acordo com este mesmo autor, era muito comum na Europa testar a eficiência das pedras bezoares dando-as a animais previamente envenenados.

Na opinião do jesuíta, bezoares falsos eram produzidos tão perfeitamente no Oriente que se tornava muito difícil reconhecer os legítimos, a não ser rompendo-0s, mas que "en el occidente no se practica semejante sophysteria" ${ }^{45}$ Os bezoares legítimos eram demasiadamente caros e, por esta razão, Sánchez Labrador adverte sobre a ocorrência de falsificações destas pedras e condena sua utilização como amuletos protetores. Na Alemanha, segundo ele, as pedras de águias eram empregadas para facilitar os partos, e na França, se fazia uso do bezoar de calamite ${ }^{46}$ para diminuir a febre, enquanto que "En Italia también hay Boticarios, y médicos, impostores, que en los males extremos, ordenan a los enfermos, que beban el agua, en que por algún tiempo haiga estado en infusión una de esas piedras del Puerco espín (Cui)". ${ }^{47}$ De acordo com 0 jesuíta, a utilização desta infusão atestava a credulidade humana, não produzindo qualquer benefício ao doente. Mas, em alguns casos, ele adverte, podiam ser encontradas pedras na vesícula e na bexiga das cabras, denominadas de Pseudo-Bezoares, que possuíam virtudes sudoríferas semelhantes às encontradas nas verdadeiras.

Mas não apenas as pedras falsificadas eram contestadas, também os bezoares tidos como verdadeiros passaram a ter criticada sua ação contra certas enfermidades e, especialmente, envenenamentos. Sánchez Labrador refere a opinião do médico Robert James, ${ }^{48}$ para quem as experiências com os bezoares haviam demonstrado que: "Estas piedras ni tienen olor, si sabor, y tomadas por la boca, no causan sensación ninguna, ni producen el más mínimo efecto sensible. Razon suficiente para hazer crer, que no gozan virtud alguna por más que los Physicos las prescriban, y en mayor cantidad, de la que señala Schröder". ${ }^{49}$ De acordo com o missionário jesuíta, existiam muitas circunstâncias que contribuíam para que as virtudes das pedras bezoares fossem colocadas em dúvida, levando alguns, como o médicocirurgião alemão Guillermo Fabrício Hildano (1560-1630), a afirmar que elas, ao invés de trazerem benefícios para a saúde, causariam várias enfermidades, como a febre quartana.

Diferentemente dos estudiosos do período, como Esteban Geoffroy, Nicolas Lemery, ${ }^{50}$ Guillermo Piso e Georg Marcgrav, Sánchez Labrador não acreditava na inferioridade do bezoar ocidental e do americano, ressaltando, inclusive, sua superioridade em relação ao oriental. Geoffroy rechaçava e reprovava a utilização dessas pedras, observando que, caso fosse necessário usá-las, a quantidade deveria ser muito superior a dos bezoares orientais, vistos como mais eficazes. Já Piso e Marcgrave, apesar de afirmarem que os cervos do Brasil produziam pedras bezoares inferiores às orientais, irão ressaltar sua bem sucedida utilização contra venenos pelos indígenas.

Sánchez Labrador, por sua vez, afirma que a pedra bezoar natural e genuína da América estava dotada de mais virtudes medicinais do que as das encontradas e vendidas na Europa. De acordo com o jesuíta, as pedras bezoares americanas eram melhores e preferíveis às orientais por não serem falsificadas, pois

En el Paraguay las logramos sin adulteraciones, ni imposturas: todas son Naturales, y genuinas. En España un H. Jesuita, muy inteligente en la Pharmacia, que exercía en el Colegio de la Insigne Universidad de la Salamanca, habido hecho todas las pruebas en orden a experimentar las virtudes delos Bezoares del Paraguay, los depuso a los orientales, y pidió con instancias, que le remitiesen otras de estas Piedras en cantidad. ${ }^{51}$ 
Ao longo de vários capítulos do Paraguay Natural Ilustrado, o jesuíta destaca que tanto o bezoar ocidental, quanto o bezoar oriental possuíam suas virtudes relacionadas com a quantidade de sal volátil alcalino e sulfúreo que continham, sendo também bastante oleosos e contribuindo para a limpeza dos ácidos do corpo. Por possuírem estas propriedades, os bezoares seriam diaforéticos, provocariam o suor, sendo bons contra os venenos, dissipando as vertigens da cabeça e as palpitações do coração, e matando as lombrigas. 0 jesuíta recomenda que as pedras fossem reduzidas a pó e que as doses deveriam ser de quatro até seis grãos tomados pela boca ou, então, a pedra embebida em algo que o jesuíta denominou de conveniente. Outra orientação dada por Sánchez Labrador era a de que as pedras bezoares deveriam ser escolhidas por sua grandeza moderada e por sua cor aproximada, sendo que as não falsificadas deveriam soltar uma tintura amarelada ou esverdeada, não se desfazendo ao serem colocadas na água.

Vale ressaltar que o jesuíta Sánchez Labrador compreende as virtudes medicinais atribuídas às pedras bezoares a partir de pressupostos da teoria humoralista hipocrático-galênica, ${ }^{52}$ segundo a qual a saúde era assegurada pelo equilíbrio entre os humores que compunham o corpo humano. Desta forma, existia a concepção de que as enfermidades eram causadas justamente pelo excesso ou ausência de algum dos humores, o que levava a práticas que visavam à expulsão desses humores através do sangue, das fezes, da urina, do vômito e de demais formas de excreção. Por esta razão, eram largamente utilizadas na Europa as práticas terapêuticas de purgar, fazer sangrias, causar vômitos e provocar urina. ${ }^{53}$

A associação das virtudes terapêuticas tanto das pedras bezoares, quanto de outros medicamentos com a teoria hipocrático-galênica não foi feita unicamente por Sánchez Labrador, sendo comum entre os estudiosos do século XVIII e dos séculos anteriores. No caso específico da pedra bezoar, o autor destaca que ela "[...] promueve la transpiración, 0 sudor, resiste a la malignidad de los venenos [...]", ${ }^{54}$ evidenciando sua concepção de que ela apresentava propriedades terapêuticas porque promovia, através da transpiração do corpo, a eliminação dos humores que estavam causando a enfermidade. ${ }^{55}$ Segundo a historiadora argentina Maria Silvia Di Liscia, ${ }^{56}$ as pedras bezoares eram tidas como essenciais nas boticas europeias e americanas, sendo também referidas nas farmacopéias, nos compêndios e receituários da Companhia de Jesus e nas listas de mercadorias solicitadas aos Procuradores da ordem que se dirigiam à Europa. $\mathrm{A}$ utilização de pedras bezoares é referida em ao menos duas receitas na Materia Medica Misionera, escrita pelo irmão jesuíta Pedro Montenegro (1710), encarregado da botica do Colégio de Córdoba. Numa delas, a pedra é utilizada contra a varíola, juntamente com quatro folhas de calamita menor (planta equisetínea) e duas onças de açúcar, o que provocava suores nos pacientes, razão pela qual o boticário recomendava que estes se resguardassem do vento. Em outra receita, Montenegro faz menção ao seu uso combinado com folhas da sextula maior: "E se lhe colocam umas duas folhas de borragem [borracha-chimarrona] ou de pedra bezoar, por ser mais sudorífica, atenua as dores internas, assim do ventrículo como do fígado". ${ }^{57}$

0 inventário do Colégio de Córdoba, realizado logo após o decreto de expulsão da Companhia de Jesus, nos anos de 1771 e 1772, confirma que as pedras bezoares integravam "los bienes medicinales" das boticas deste colégio jesuítico da Província Jesuítica do Paraguai. As pedras aparecem relacionadas na categoria Preparaciones y Polvos, ao lado de chifres de cervo, dentes de javali, corais e olhos de caranguejo, pós de víbora e esperma de baleia, e, ainda, na categoria dos Polvos cordiales, na qual é feita, inclusive, uma distinção entre a pedra bezoar ocidental e a americana, que aparecem, mais uma vez, relacionadas entre outros itens, tais como corais, madrepérola e olhos de caranguejo.$^{58}$ Em estudo sobre as boticas da capitania de Minas Gerais setecentista, a historiadora Junia Ferreira Furtado também constatou que eram utilizados:

(...) entre outros bezoárticos, o âmbar gris, que se formava no intestino de cachalotes; a pedra de porco-espinho, "considerada o mais eficaz dos bezoares do Oriente e indicada nos casos de vômitos, fraqueza de estômago, aflições do coração, afetos uterinos das mulheres, 'paixões dos rins', retenção de urina e febres malignas. No Brasil, essa preciosidade era fornecida pelos porcos-do-mato'. As pedras encontradas na cabeça do jacaré eram utilizadas no combate à febre; a pedra lipes servia 'para consumir as carnes supérfluas das chagas e para curar as da boca'; a pedra-ume suspendia as diarréias após a evacuação dos humores. ${ }^{59}$ 
Já os olhos de caranguejo, referidos no inventário da botica do colégio de Córdoba, figuram entre os medicamentos empregados "nos problemas estomacais, de rins e bexiga". ${ }^{60}$ Também o inventário do colégio do Rio de Janeiro, realizado no ano de 1759, revela que as pedras bezoares ou Bezuarticas podiam ser encontradas nas prateleiras de sua botica, aparecendo entre os remédios que, na opinião do inventariante, deveriam ser colocados à venda "por serem couzas corrutiveiz" ${ }^{61}$

\section{Considerações finais}

A obra Paraguay Natural Ilustrado foi escrita por Labrador entre os anos de 1771 e 1776, portanto, durante seu exílio em Ravena. Obrigado a deixar a América junto com os demais companheiros de ordem e impedido de trazer consigo suas anotações, o padre jesuíta precisou recorrer a sua memória e a obras e documentos disponíveis nas bibliotecas européias para escrevê-la. 0 diálogo que mantém com autoridades reconhecidas por seus estudos de Medicina, Farmácia ou de História Natural, tanto referências clássicas, quanto do século XVII ou contemporâneas a ele confirma esta consulta. Dentre os referidos por Labrador estão Esteban Geoffroy, Jacobo Boncio, Gaspar Bauhin, Robert James, Johann Schröder, padre Alonso de Ovalle S.J. e Nicolas Lemery.

Ao referir estes autores e destacar as posições assumidas em algumas de suas obras, Labrador o faz tanto para legitimar as informações sobre a natureza americana presentes em sua obra, quanto para contestar algumas das afirmações feitas pelos estudiosos que refere. Ao contestar certas autoridades, o jesuíta também está reivindicando 0 conhecimento e legitimando seu trabalho, tentando ocupar seu lugar como autor produtor de ciência. Vale lembrar, aqui, que nos séculos XVII e XVIII, segundo Chartier, "A autenticação de experimentos ou descobertas exigia a garantia dada por uma autoridade gradualmente deslocada do poder aristocrático ou principesco para o poder da autoria científica" ${ }^{62}$

Como já observado, ainda que, na Europa, as pedras bezoares estivessem sendo contestadas, devido às frequentes falsificações, Sánchez Labrador se empenhou em comprovar as virtudes terapêuticas das americanas, dissociando-as de poderes mágicos. 0 jesuíta também criticou os autores que as reprovavam, como Geoffroy, que afirmava que as pedras ocidentais e as americanas eram inferiores se comparadas às orientais. Para Sánchez Labrador, as pedras bezoares americanas, especialmente, as encontradas no Paraguai, eram mais eficazes do que as retiradas dos estômagos das cabras persas e europeias.

Cabe lembrar que na Europa da segunda metade do Setecentos, o discurso científico produzido sobre a América estava fundamentado no determinismo climático e na teoria da degeneração e inferioridade da natureza e da população americana. Huffine ${ }^{63}$ afirma que os padres jesuítas da Província Jesuítica do Paraguai, como de outras províncias, repudiavam tais teorias e buscavam, através de seus trabalhos, comprovar que estavam erradas. Sánchez Labrador foi um destes autores que argumentaram contra os cientistas europeus "sugerindo que a vida vegetal e animal da América era saudável, resistente e auto-suficiente [...]". ${ }^{64}$ Suas opiniões a favor das pedras bezoares ocidentais e contra as teses de inferioridade defendidas por autores europeus evidenciam esta posição que assumiu em defesa da natureza americana. 
Eliane Cristina Deckmann Flecké doutora em História pela PUCRS (Porto Alegre, RS), Coordenadora do Programa de Pós-Graduação em História e Professora Titular da Graduação e do PPGH da UNISINOS, onde desenvolve investigações vinculadas à Linha de Pesquisa Sociedades Indígenas, Cultura e Memória. É pesquisadora do CNPq (P02) e integra os Grupos de Pesquisa-CNPq Jesuítas nas Américas e/magens da Morte: a morte e o morrerno mundo ibero-americano. E-mail: ecdfleck@terra.com.br.

1 Agradeço a colaboração, em especial na transcrição do manuscrito, de Mariana Alliatti Joaquim, Graduanda do Curso de História da Universidade do Vale do Rio dos Sinos (UNISINOS), que atua como bolsista de Iniciação Científica no projeto As "artes de curar" em dois manuscritos jesuíticos inéditos do século XVIII, financiado pelo Edital Ciências Humanas e Sociais - Chamada MCTI/CNPq/MEC/CAPES NN 22/2014.

2 MORENO, Aníbal Ruiz. La Medicina en "el Paraguay Natural" (1771-1776) del P. Jose Sanchez Labrador S. J. Exposición comentada del texto original. Tucuman: Universidad Nacional de Tucuman, 1948.

3 SAINZ OLLERO, Héctor; CARDONA, Francisco Suárez; ONTAÑóN, Miguel Vázquez de Castro. José Sánchez Labrador y los naturalistas jesuitas del Río de la Plata. Madrid: Mopu, 1989.

4 Antonio Machoni ingressou na Companhia de Jesus em 1688 e dez anos depois foi enviado para atuar como missionário nas reduções do Paraguai. Em 1711 , passou a atuar entre os indígenas Lules da redução de San Antonio de Valbuena e, em 1714, funda a redução de San Esteban de Miraflores. Foi professor e, posteriormente, reitor do Colégio Máximo de Córdoba, até 1728, ano em que foi enviado à Espanha e à Itália, como Procurador da Província Jesuítica do Paraguai. Regressou ao Rio da Plata em 1733, juntamente com outros 30 noviços, irmãos e padres, dentre os quais, se encontrava José Sanchez Labrador. Em 1739 é designado Provincial da Província Jesuítica do Paraguai, permanecendo no cargo até 1743. Faleceu, em Córdoba, dez anos depois.

5 Os jesuítas foram expulsos das áreas coloniais do Império em 1767, em cumprimento ao Decreto de 27 de fevereiro, assinado por Carlos III. A expulsão da Companhia de Jesus fazia parte de um conjunto de reformas da Coroa espanhola, conhecido como Reformas Bourbônicas, que tinha como objetivo aumentar o controle do poder real sobre os domínios ultramarinos. Antes de Carlos III, outro déspota esclarecido, d. José I, de Portugal, havia expulsado os jesuítas dos seus domínios, em 1759, também buscando subordinar o clero ao Estado.

6 Sobre esta última viagem realizada pelo jesuíta em território americano, Furlong afirma que Labrador teria sido o primeiro a fazer o caminho que ligava as reduções de Guaranis às de Chiquitos.

7 José Sanchez Labrador e os outros cerca de dois mil jesuítas expulsos da América espanhola foram exilados e se estabeleceram em outras localidades da Europa. Os padres do Vice-reinado do Rio da Prata teriam sido os últimos a deixarem as reduções pelas dificuldades de se encontrarem substitutos, sendo retirados de suas residências entre junho e agosto de 1768. Os documentos encontrados com os jesútas foram confiscados para que pudessem ser encontradas evidências sobre suas atividades, razão pela qual foram autorizados a viajar somente com suas roupas e breviários. Foram levados, em precárias condições, para Córsega, de onde foram enviados, em sua maioria, para as cidades de Faenza, Ravena, Brisighella e Ímola. Em uma carta datada de 21 de agosto de 1768, de Puntales (Cádiz), encontra-se uma lista de 150 jesútas que partiram de Buenos Aires, em uma fragata, chamada de Esmeralda, que os levaria de volta para a Europa, sob responsabilidade do comandante Mateo del Collado Neto. Sanchez Labrador estava citado entre os missionários que provinham da Província do Paraguai.

8 Como informado, a obra se mantém inédita até os dias de hoje, razão pela qual nos valemos de uma cópia digitalizada do manuscrito, que se encontra no Arquivo Romano da Sociedade de Jesus (ARSI), em Roma.

9 SÁNCHEZ LABRADOR, José. Paraguay Natural. Ilustrado. Noticias del pais, con la explicación de phenomenos physicos generales y particulares: usos útiles, que de sus producciones pueden hacer varias artes. Parte Tercera, contiene los libros siguientes. I. Animales Quadrupedes. II. Las Aves. III. Los Peces. (Manuscrito inédito), Ravenna, 1771, 128 p.

10 Ver mais em: ALVES, Jorge Manuel dos Santos. A pedra-bezoar - realidade e mito em torno de um antídoto. In: ALVES, Jorge M. dos Santos, GUILLOT, Claude; PTAK, Roderick (coord.). Mirabilia Asiática: Produtos raros no comércio marítimo. Wiesbaden: Harrassowitz Verlag \& Fundação Oriente, 2003, p. 121-134. Para este autor, as pedras bezoares eram conhecidas pelos chineses desde a Antiguidade, podendo ser encontradas em lendas da dinastia Zhou do Leste (770-256 a. C.).

11 ALMEIDA, Carla B. S. de. Medicina mestiça: saberes e práticas curativas nas Minas setecentistas. São Paulo: Annablume, 2010, p. 113.

12 "Qualquer medicamento, bebido como xarope, ou purga, ou aplicado como emprasto [sic]". BLUTEAU, Raphael (1712-1728). Vocabulario portuguez \& latino: aulico, anatomico, architectonico. Coimbra: Collegio das Artes da Companhia de Jesus, 8 v. Disponível em: <http://www.brasiliana.usp.br/ dicionario/edicao/1 >. Acesso em: 15 de setembro de 2014, p. 475.

130 médico Jacobo Boncio (?-?) atuou a serviço da Companhia Holandesa, em Java. BIOGRAFIAS. Universidade Federal de Campina Grande. Disponível em: $<$ http://www.uaec.ufcg.edu.br/>. Acesso em: 20 set. 2014.

140 médico e naturalista holandês Guillermo Piso (1611-1678) realizou expedição à América portuguesa, permanecendo no nordeste brasileiro no período de 1637 a 1644, tendo atuado, também, com médico particular do conde Maurício de Nassau. Escreveu, juntamente com Georg Marcgrav, a obra Historia Naturalis Brasilieae (1648), primeira publicação científica sobre a geografia e natureza do Brasil. Ver mais em: PICKEL, D. Bento José. Flora do Nordeste do Brasil segundo Piso e Marcgrave: no século XVII. Argus Vasconcelos de Almeida (Editor). Recife: EDUFRPE, 2008.

150 alemão Georg Marcgrav (1610-1644) tinha formação em matemática, história natural, astronomia e medicina. Durante sua permanência no Brasil realizou uma série de viagens exploratórias, sob o patrocínio de Maurício de Nassau. Delas resultou a obra, escrita juntamente com Guilhermo Piso, Historia Naturalis Brasilieae, de 1648. Ver mais em: PICKEL, op. cit., 2008

16 SANCHEZ LABRADOR, op.cit., 1771, p. 50.

17 Em sua obra Conquista espiritual, de 1639, o padre Antônio Ruiz de Montoya fornece informações sobre as práticas curativas adotadas pelos indígenas da Província Jesú́tica do Paraguai: "Usam os índios muitos remédios e ervas medicinais que lá a natureza tem produzido. A pedra de São Paulo é de ajuda comprovada; são-no também os alhos esmagados, ingerido o remédio como bebida; a pedra bezoar e outras ervas medicinais". MONTOYA, Antonio Ruiz. Conquista espiritual. Porto Alegre: Martins Livreiro. 1985, p. 25. 
180 padre jesuíta José Cardiel nasceu em La Guardia, em 1704. Desembarcou em Buenos Aires, em 1729 e, dois anos depois, passou a atuar como missionário nas reduções de indígenas guaranis. De 1729 a 1767, missionou também entre os abipones, mocobis, charruas, pampas e serranos, vindo a falecer no exílio, em Faenza, na Itália, em dezembro de 1782.

19 CARDIEL apud FURLONG, Gillermo. Entre los Pampas de Buenos Aires (Según noticias de los misioneros jesuitas Matías Strobel, José Cardiel, Tomás Falkner, Jerónimo Rejón, Joaquín Caamaño, Manuel Querini, Manuel Gracia, Pedro Lozano y José Sánchez Labrador). Buenos Aires: Talleres Gráficos San Pablo, 1938, p. 28.

20 Ver mais em: JOLIS, José. Ensayo sobre la Historia Natural del Gran Chaco: Resistência: Instituto de Historia de la Universidad Nacional del Nordeste, [1789], 1972. Sobre Jolis, sabe-se que nasceu na Espanha, em 1728, e que foi missionário na região oeste do Chaco. Foi durante o exílio, em Faenza, que ele dedicou-se a escrever, a partir das memórias das viagens que realizou pela região, a obra Ensayo sobre la Historia Natural del Gran Chaco, finalizada em 1789, um ano de sua morte.

210 autor de $A$ description of Patagonia and adjoins parts of South America, publicada em Hereford, em 1774, nasceu em Manchester, Inglaterra, no ano de 1702. Na condição de médico, iniciou viagem para a América, em 1730. Chegou ao Rio da Prata a bordo de um navio negreiro e, adoentado, foi socorrido pelo padre Sebastián de San Martin, o que o levou a se converter ao catolicismo e a ingressar na Companhia de Jesus em 1732. Atuou como médico e boticário no Colégio de Córdoba, onde se encontrava quando do decreto de expulsão de Carlos III. Não se conhecem as circunstâncias de seu regresso à Inglaterra, mas foi lá que faleceu em janeiro de 1784.

22 FALKNER, Thomas. Descripción de Patagonia y de las partes adyacentes de la América meridional con la religión, política, costumbres y lenguas de sus moradores y algunas particularidades relativas a las islas Malvinas. Buenos Aires: Imprenta del Estado, [1774], 1836, p. 30-31.

23 Alonso de Ovalle foi um destacado cronista e missionário jesuíta, natural de Santiago do Chile. Como Procurador da Vice-Província Jesuítica do Chile, percorreu cidades da Espanha e da Itália em busca de missionários. Sua obra Historica Relacion del Reyno de Chile foi publicada em Roma, em 1646. De acordo com Espíndola (1974, p. 30), ele "pasó diez años buscando jesuitas y para remediar la ignorancia que había sobre Chile, escribió su Histórica Relación."

24 SANCHEZ LABRADOR, op. cit., 1771, p. 49.

25 Pedro Lozano nasceu em Madri, em 1697, e ingressou na Companhia de Jesus em 1711. Chegou à América em 1714 e no ano seguinte passou a atuar como professor de Filosofia e Teologia em Córdoba, função que exerceu até 1724. A partir de 1730, aparece no catálogo da Ordem como "historiographus provinciae", ocupação que exerceu até sua morte, em Humahuaca, no ano de 1752.

26 De acordo com Josefina Cargnel, “Esta obra es la introducción que Lozano agrega a la Historia de la Compañía de Jesús en el Paraguay encargada por sus superiores; en 1745, por razones no expuestas en las consultas de la Orden, los superiores jesuitas separaron este escrito consagrado a los "sucesos profanos" remitiendo el resto a Europa para que fuera editado. Probablemente las razones económicas primaron para no publicar una obra tan extensa; recordemos los costos de edición de una obra de más de mil páginas, que no había sido encargada por la Orden y por lo tanto no habría respondido a los objetivos que se perseguían con la misma." Ver mais em: GARGNEL, Josefina. La restitución de la "Historia de la conquista de las provincias del Paraguay, Río de la Plata y Tucumán". Pedro Lozano S. J. (1745). Disponível em: http://www.unne.edu.ar/unnevieja/Web/cyt/com2005/2-Humanidades/H-008.pdf

27 LOZANO, Pedro. Historia de la Conquista del Paraguay, Río de la Plata y Tucumán, I a V. Buenos Aires: Imprenta Popular. [1745], 1873, p. 282-283. Dísponivel em: http://www.portalguarani.com/2647_pedro_lozano/22156_historia_de_la_conquista_del_paraguay_t i_por_el_padre_pedro_lozano.html

28 Trata-se de um "Mamífero del orden de los Roedores, parecido al conejo, pero más pequeño, con orejas cortas, cola casi nula, tres dedos en las patas posteriores y cuatro en las anteriores. Se usa mucho en experimentos de medicina y bacteriologia". Dicionario de la Real Academia Española. Disponível em: <http://lema.rae.es/drae/?val=agujerar > . Acesso em: 22 de Setembro de 2014.

29 Os primeiros jesuítas que chegaram ao Chile em 1593 estiveram sujeitos à jurisdição da Província Jesuítica do Peru até 1607, quando foi criada a Província Jesuítica do Paraguai, que passou a controlar a atuação dos missionários na região. Esta situação manteve-se até 1624, ano em que foi criada a ViceProvíncia Jesuítica do Chile, subordinada novamente à Província do Peru. Em 1683 foi criada a Província Jesuítica do Chile.

30 SANCHEZ LABRADOR, op. cit., 1771, p. 49.

31 Evidenciando não apenas sua larga utilização, mas também sua circulação, através do comércio, algumas boticas instaladas em colégios jesuíticos do Peru - como a do Colegio San Pablo, de Lima - enviavam medicamentos - como o bezoar peruano, a ambrosia mexicana e a quina - para estabelecimentos da Companhia de Jesus no Chile, Paraguai, Argentina, Equador, Panamá e no Velho Mundo. Ver mais em: FLECK, Eliane Cristina Deckmann; POLETTO, Roberto. Circulação e produção de saberes e práticas científicas na América meridional no século XVIII: uma análise do manuscrito Materia Medica Misionera de Pedro Montenegro (1710). Hist. cienc. saude-Manguinhos [online]. 2012, vol. 19, n. 4, p. 1121-1138.

320 droguista Pierre Pomet nasceu em Paris, em 1658, falecendo na mesma cidade em 1699. É o autor de Histoire générale des drogues, de 1694, obra que recebeu traduções para o inglês e para o alemão, logo após sua publicação.

330 suíço Gaspar Bauhin (1560-1624) atuou como naturalista e médico, dedicando-se a estudos de botânica. BIOGRAFIAS. Universidade Federal de Campina Grande. Disponível em: < http://www.uaec.ufcg.edu.br/> . Acesso em: 20 de setembro de 2014.

34 Ver mais em: CARNEIRO, Henrique. 0 Saber Fitoterápico Indígena e os Naturalistas Europeus. Fronteiras, Dourados, MS, v. 13, n. 23, jan.jun. 2011, p. 13-32.

35 ALVES, op. cit., 2003, p. 126

36 SANCHEZ LABRADOR, op. cit., 1771, p. 59.

37 Sobre as pedras bezoares formadas nos estômagos dos porcos-espinhos, recomenda-se ver mais em: BORSCHBERG, Peter. 0 comércio, uso e falsificação dos bezoares de porco-espinho na Época Moderna". Oriente (Lisboa), n. 14, 2006, p. 60-78.

38 SANCHEZ LABRADOR, op. cit., 1771, p. 48.

39 Trata-se de "Pylôro (Termo Anatomico) He o orifício inferior do estomago, u ventrículo, pelo qual os alimentos convertidos em chylo paslao para os intestinos". BLUTEAU, op. cit., 1728, p. 839.

40 Trata-se do químico e médico Esteban Francisco Geoffroy (1672-1731), que tem sua obra Matéria Médica referida com frequência por Sanchez Labrador. Ver mais em: MORENO, op. cit., 1948, p. 22. 
41 SÁNCHEZ LABRADOR, José. Paraguay Natural. llustrado. Noticias del pais, con la explicación de phenomenos physicos generales y particulares: usos útiles, que de sus producciones pueden hacer varias artes. Parte Segunda, contiene los libros siguientes. I. Botanica, o delas Plantas em general. II. Selvas, Campos, y Pradarias del Paraguay. III. Los Arboles en Particular. IV. Palmas, Tunas, y Cañas. V. Ycipos, y otras Plantas sarmentosas. VI. Algunos Arbolillos, Matorrales, y Hierbas. VII. Algunos utiles, y curiosidades. (Manuscrito inédito), Ravenna, 1771, p. 170.

42 "Astilla o raja de madera muy impregnada en resina, que, encendida, alumbra como un hacha". Dicionario da Real Academia Española. Disponível em: $<$ http://lema.rae.es/drae/?val= corcion > . Acesso em: 23 de setembro de 2014

43 Trata-se de "Substância de cheiro penetrante, persistente, obtida de uma bolsa situada sob a pele do abdome do almiscareiro macho e usada principalmente em perfumes como fixativo". Dicionário Michaelis. Disponível em: <http://michaelis.uol.com.br/moderno/portugues/index.php?lingua=portuguesportugues\&palavra $=$ alm\%EDscar $>$. Acesso em: 18 Setembro 2014.

44 ALVES, op. cit., 2003, p. 128-129

45 SANCHEZ LABRADOR, op. cit., 1771, p. 55.

46 Trata-se de um "Sapo pequeño, verde, con una línea amarilla a lo largo del dorso". Dicionario de la Real Academia Española. Disponível em: < http://lema. rae.es/drae/?val=agujerar> . Acesso em: 22 de setembro de 2014

47 SANCHEZ LABRADOR, op. cit., 1771, p. 59

480 médico e físico inglês Robert James (1703-1773/1776) é o autor de Farmacopea Universal e Dicionário Médico (1743), obras mencionadas por Sanchez Labrador em Paraguay Natural Ilustrado. Ver mais em: MORENO, op. cit., 1948, p. 21

49 SANCHEZ LABRADOR, op. cit., 1771, p. 56. Nesta passagem, o jesuíta faz referência ao médico alemão Johann Schröder (1600-1664).

500 químico francês Nicolas Lemery (1645-1715) era membro da Academia de Ciências. Sanchez Labrador refere suas obras Farmacopea Universal (1697), Tratado Universal das drogas simples (1698), Tratado do Antimônio (1707) e Nova Recopilação de segredos e curiosidades mais raros (1709). Ver mais em: MORENO, op. cit., 1948, p. 21

51 SANCHEZ LABRADOR, op. cit., 1771, p. 57.

52 De acordo com essa teoria, o corpo humano seria formado por diferentes líquidos ou humores que eram "quase sempre quatro (Sangue, Fleuma, Bílis Amarela e Bílis Negra). A saúde consistiria no equilíbrio desses humores, assim como a enfermidade consistiria no predomínio de algum deles sobre os demais". Ver mais em: FREITAS REIS, Ivoni. Um mapa da medicina antiga: Entre a cura através dos contrários e a cura através dos semelhantes. Revista de historia de la medicina y epistemologia medica. Buenos Aires, Departamento de Humanidades Médicas, v. I, p. 01-14, 2009, p. 3.

53 De acordo com ALVES (2003), se consumidas após serem diluídas em água quente, água de coco ou quando fervidas em vinho de palmeira, as pedras bezoares eram excelente remédio para as depressões, as febres altas, a lepra, varíola, sarampo, cólera, ajudando a facilitar também os partos e na recuperação das parturientes.

54 SÁNCHEZ LABRADOR, op. cit., 1771, p. 56.

55 A historiadora argentina Cintia Natalia Rosso, em artigo que aborda as epidemias de varíla nas reduções chaquenhas de indígenas abipones e mocobis, informa que "En Europa los remédios más comúnmente utilizados para la viruela eran las sangrías, la aplicación del calor, la provocación de sudor y la llamada 'cura roja'." Ainda de acordo com Rosso, o padre jesuíta Martin Dobrizhoffer, em sua obra História de Los Abipones, de 1784, teria mencionado a indicação do uso de pedras bezoares no tratamento da varíola pelo médico alemão Johann Jacob Woyts [em obra de 1727], o que parece se justificar, já que eram empregadas como "modelo terapêutico netamente extractivo de los 'malos humores' corporales." Ver mais em: ROSSO, Cintia Natalia. Epidemias de viruela en las reducciones chaqueñas de abipones y mocovíes durante siglo XVIII. Eä. Vol. 2, № 3 (Abril/April 2011), p. 1-28. Disponível em: www.ea-journal.com

56 Ver mais em: DI LISCIA, María Silvia. Introducción. Capítulo1. La Medicina Indígena como clave de interpretación religiosa, política y científica. In: DI LISCIA, María Silvia. Saberes, Terapias y Prácticas Médicas en Argentina (1750-1910). Madrid: Consejo Superior de Investiga Científicas. Instituto de Historia, 2002, p. 1-51.

57 MONTENEGRO, Pedro. Materia Medica Misionera. Buenos Aires: Imprenta de la Biblioteca Nacional. [1710], 1945, p. 142.

58 FLECK, Eliane Cristina Deckmann. Entre a caridade e a ciência: a prática missionária e cientifica da Companhia de Jesus (América platina, séculos XVII e XVIII). São Leopoldo: Oikos; Editora Unisinos, 2014, p. 330-340.

59 FURTADO, Junia Ferreira. Barbeiros, cirurgiões e médicos na Minas Colonial. Revista do Arquivo Público Mineiro, vol. 41, jul./dez., 2005, p. 103. Sobre este tema recomenda-se ver mais em: EDLER, Flávio Coelho. Boticas \& Pharmacias. Uma historia ilustrada da Farmácia no Brasil. Rio de Janeiro: Casa da Palavra, 2006 e ABREU, Jean Luiz Neves. Nos domínios do corpo. 0 saber luso-brasileiro no século XVIII. [on line]. Rio de Janeiro: Editora FIOCRUZ, 2011. Disponível em: http://books.scielo.org

$60 \quad$ FURTADO, op. cit., 2005, p. 104.

61 Livro de Tombo do Colégio de Jesus do Rio de Janeiro. Rio de Janeiro: Biblioteca Nacional, 1968, p. 124-170.

62 CHARTIER, Roger; FAULHABER, Priscila; LOPES, José Sérgio Leite (Orgs.). Autoria e História Cultural da Ciência. Rio de Janeiro: Beco do Azougue, 2012, p. 62.

63 HUFFINE, Kristin. Raising Paraguay from Decline: Memory, Ethnografy, and Natural History in the Eighteenth-Century Accounts of the Jesuit Fathers. In: FIGUEROA, Luis Millones; LEDEZMA, Domingo (eds.). El saber de los jesuitas, historias naturales y el Nuevo Mundo. Madrid: Iberoamericana, 2005. p. 279302.

64 HUFFINE, op. cit., 2005, p. 286-287, tradução nossa.

[Recebido em Agosto de 2015. Aprovado para publicação em Dezembro de 2015] 